\title{
ESTUDO EXPERIMENTAL E MODELAGEM TERMODINÂMICA DE DADOS DE EQUILÍBRIO LÍQUIDO-VAPOR DE COMPOSTOS GRAXOS A PARTIR DA CALORIMETRIA EXPLORATÓRIA DIFERENCIAL
}

\author{
RAFAEL M. MATRICARDE. FALLEIRO ${ }^{1}$, LUCIANA Y. AKISAWA SILVA ${ }^{1}$, ANTONIO J. A. \\ MEIRELLES $^{2}$ e MARIA A. KRÄHENBÜHL ${ }^{3}$ \\ ${ }^{1}$ Universidade Federal de São Paulo, Departamento de Ciências Exatas e da Terra \\ ${ }^{2}$ Universidade Estadual de Campinas, Departamento de Engenharia de Alimentos \\ ${ }^{3}$ Universidade Estadual de Campinas, Departamento de Desenvolvimento de Processos e Produtos \\ E-mail para contato: falleiro@unifesp.br
}

\begin{abstract}
RESUMO - Este estudo visa contribuir com dados inéditos de equilíbrio líquido-vapor de alguns compostos que constituem o biodiesel e que são inviáveis economicamente de serem determinados por técnicas convencionais. Neste trabalho, a Calorimetria Exploratória Diferencial (DSC) adaptada a um sistema de vácuo foi empregada. Essa é uma técnica analítica de grande precisão que envolve métodos de análises térmicas, utilizando-se pequenas quantidades de amostra e um menor tempo de operação. A metodologia baseada no método da pressão total foi eficaz para a determinação da temperatura de ebulição dos sistemas propostos (Palmitato de Etila + Ácido Palmítico e Ácido Mirístico + Estearato de Etila) à pressão de $20 \mathrm{mmHg}$ utilizando-se amostras entre 4,0 e 6,0 mg em diferentes concentrações. Os modelos Wilson, NRTL e UNIQUAC permitiram descrever a não idealidade da fase líquida, a partir da determinação de parâmetros indispensáveis para aperfeiçoar os processos de purificação do biodiesel.
\end{abstract}

\section{INTRODUÇÃO}

O biodiesel vem ganhando o interesse mundial por ser um combustível biodegradável, não tóxico, com menor emissão de poluentes do que o petrodiesel, e poder ser usado diretamente nos motores a diesel já existente. Neste trabalho os dados de equilíbrio líquido-vapor de alguns compostos que constituem o biodiesel foram estudados por apresentarem aplicação nas indústrias alimentícias, farmacêutica e de cosméticos, as quais fazem uso de misturas de compostos graxos.

Dados de equilíbrio líquido-vapor de misturas de ácidos graxos (que participam como os principais reagentes para obtenção do biodiesel) com ésteres etílicos são inexistentes na literatura especializada. A grande importância desses dados para a indústria do biodiesel está relacionada com a qualidade do biocombustível. Geralmente, a qualidade pode ser influenciada por vários fatores, como por exemplo, a presença de Ácidos Graxos Livres (AGL) (Gerpen e Knothe, 2006). Portanto, nesse trabalho pretendem-se determinar dados de equilíbrio líquido-vapor de sistemas binários de ácidos 
graxos + ésteres graxos etílicos. A partir dos dados obtidos serão determinados os parâmetros de interação binária, com o objetivo de melhorar a capacidade descritiva dos modelos termodinâmicos.

Devido à rota etílica não possuir tecnologia desenvolvida e o Brasil ter um bom potencial na produção de etanol economicamente viável, o uso dessa rota torna-se um desafio de grande interesse para os objetivos envolvidos nesse projeto.

Métodos dinâmicos para medir pressão de vapor têm sido usados desde o início deste século. A ebuliometria foi e ainda é uma importante técnica para essas medidas, apresentando grande precisão nos dados (Casserino et al. 1996). No entanto, a Calorimetria Exploratória Diferencial (DSC) vem ganhando espaço nesse campo, devido às vantagens que apresenta como, por exemplo: menor tempo de operação, pequenas quantidades de amostras utilizadas nos experimentos e por permitir a obtenção de resultados com boa precisão. A partir disso, houve o interesse em aplicar esta técnica para a obtenção de diagramas de equilíbrio líquido-vapor.

A calorimetria exploratória diferencial é uma técnica térmica em que as diferenças entre o fluxo de calor de uma substância e o de uma referência são monitoradas como uma função da temperatura da amostra, enquanto ambas estão sujeitas a um programa de temperatura controlada. Atualmente, o DSC tem se tornado o mais utilizado de todos os métodos térmicos, com sucesso na determinação da transição vítrea, cristalização, fusão, estabilidade de produtos, cinética de cura e estabilidade oxidativa. Pode ser empregado no estudo das mudanças de fases líquido-vapor, sólido-vapor e sólidolíquido e medir as entalpias de vaporização, sublimação e fusão (Skoog et al., 1992).

Para representar da melhor forma possível os dados experimentais, a modelagem termodinâmica passa a ser de fundamental importância para o desenvolvimento de simuladores comerciais para o projeto de equipamentos e operação de processos. Os dados de equilíbrio líquido-vapor determinados neste estudo são do tipo P-T-x. Os parâmetros dos modelos de $G^{E}$, como Wilson e NRTL e UNIQUAC, foram ajustados aos dados experimentais com o auxílio do programa DDBSP (Dortmund Data Bank, Oldenburg/Alemanha, 2003), o qual se baseia na minimização da diferença do desvio quadrático dos coeficientes de atividade.

\section{OBJETIVO}

O objetivo deste trabalho foi determinar dados experimentais de ELV de sistemas binários de ácidos graxos com ésteres graxos etílicos através da calorimetria exploratória diferencial (DSC). Foi realizado o ajuste dos dados obtidos experimentalmente para se determinar os parâmetros de interação binária dos modelos de coeficientes de atividade e avaliou-se a qualidade dos ajustes.

\section{MATERIAIS E MÉTODOS}

\subsection{Materiais}

Os ácidos graxos saturados que foram utilizados neste estudo são: ácidos mirístico e palmítico, com pureza superior a $99 \%$ adquiridos junto à Sigma. Os ésteres etílicos palmitato de etila e estearato 
de etila também foram comprados junto à mesma empresa, apresentando o mesmo grau de pureza dos ácidos. Os cadinhos utilizados como recipiente para as amostras são de alumínio e fornecidos pela empresa TA Instruments.

\subsection{Metodologia Experimental}

A técnica consiste basicamente em se pesar uma determinada quantidade de amostra dentro do cadinho de alumínio, cuja tampa possui um pequeno furo ou pinhole e, em seguida, esse conjunto é fechado hermeticamente por uma prensa encapsuladora. Sobre o pinhole do cadinho da amostra é colocada uma pequena esfera de carboneto de tungstênio (diâmetro de 1,0 $\mathrm{mm}$ ) para evitar a prévaporização da amostra e, então, o cadinho é levado para dentro da célula de pressão juntamente com o cadinho de referência (vazio). A célula é fechada e aplica-se a pressão desejada por meio do controle de válvulas que regulam o vácuo no interior da célula. A amostra e a referência são aquecidas a uma taxa de aquecimento de $25^{\circ} \mathrm{C} / \mathrm{min}$ até $\pm 50^{\circ} \mathrm{C}$ acima da temperatura de vaporização da amostra para que a linha base após o evento térmico seja restabelecida. Finalizando o procedimento, restaura-se a célula para as condições ambiente, desligando a bomba e pressurizando a célula pela válvula de alívio.

\section{RESULTADOS E DISCUSSÕES}

A partir dos dados de pressão de vapor de ésteres etílicos (Akisawa Silva et al., 2011) e dos dados de pressão de vapor dos ácidos graxos, também obtidos por este mesmo grupo de pesquisa (Matricarde Falleiro et al., 2012), iniciou-se a investigação de possíveis sistemas binários inéditos (dados P-T-x) envolvendo ésteres e ácidos graxos.

O primeiro sistema investigado foi o ácido mirístico + estearato de etila a $20 \mathrm{mmHg}$. Neste sistema há uma diferença significativa no tamanho da estrutura molecular dos compostos, conforme se pode notar pelo próprio comportamento do diagrama de fases apresentado na Figura 1.

Com os modelos de coeficiente de atividade (NRTL, UNIQUAC e Wilson) foi possível descrever a não idealidade da fase líquida para o sistema estudado, a partir de parâmetros de interação binária de cada modelo (Tabela 1). 


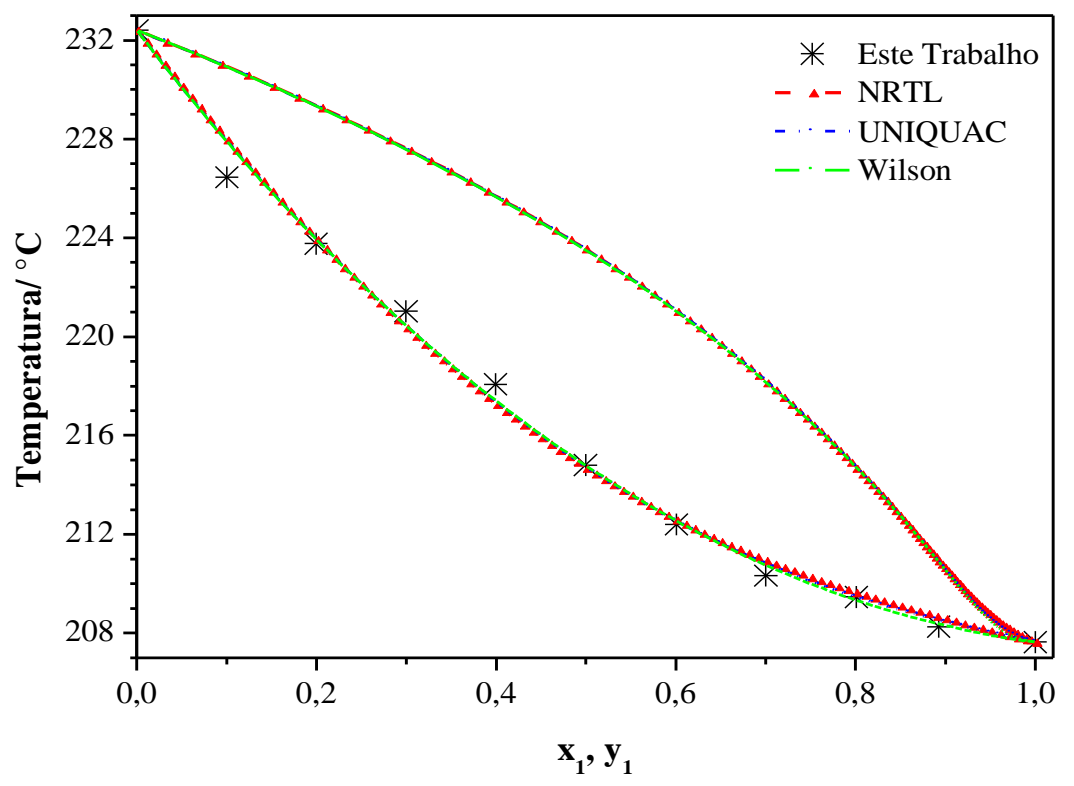

Figura 1 - Diagrama T-x-y. Sistema: ácido mirístico (1) + estearato de etila (2) a $20 \mathrm{mmHg}$.

Tabela 1 - Parâmetros de interação binária. Sistema: ácido mirístico (1) + estearato de etila (2).

\begin{tabular}{|c|c|c|c|c|}
\hline Modelos de $\mathrm{G}^{\mathrm{E}}$ & $\mathrm{A}_{12}\left(\mathrm{cal}^{\mathrm{mol}}{ }^{-1}\right)$ & $\mathrm{A}_{21}\left(\mathrm{cal.mol}^{-1}\right)$ & $\alpha_{12}$ & $\begin{array}{c}\text { Desvio Absoluto } \\
\text { Médio em } T\left({ }^{\circ} \mathrm{C}\right)\end{array}$ \\
\hline NRTL & 2117,0112 & $-953,8114$ & 0,2854 & 0,52 \\
\hline UNIQUAC & 695,2518 & $-469,6851$ & - & 0,43 \\
\hline Wilson & $-560,0491$ & 2024,1212 & - & 0,41 \\
\hline
\end{tabular}

No caso do sistema palmitato de etila (1) + ácido palmítico (2) na mesma condição de pressão, o diagrama mostrou-se diferente do anterior em vista da diferença de temperatura dos compostos puros diminuírem a área da região bifásica, conforme apresentado na Figura 2.

Constatou-se também para este último sistema que os modelos de coeficientes de atividades puderam representar satisfatoriamente os dados experimentais, já que os desvios absolutos médios para a temperatura foram relativamente baixos em cada um dos modelos ajustados. 


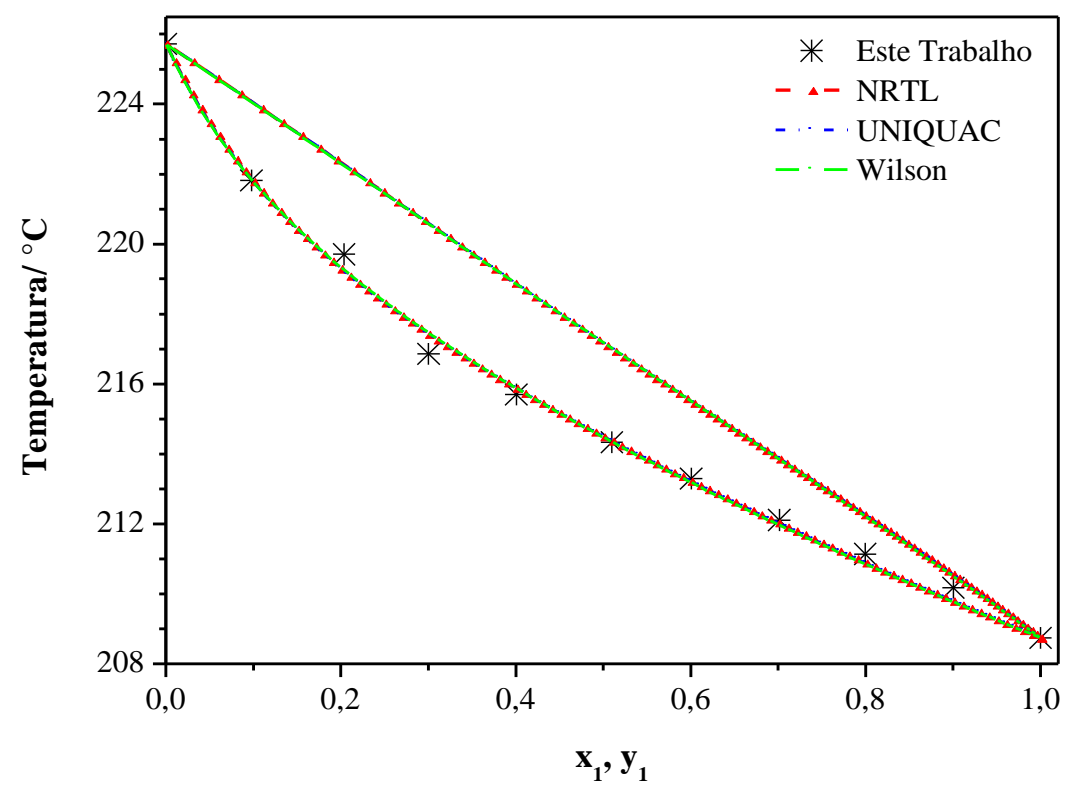

Figura 2 - Diagrama T-x-y. Sistema: palmitato de etila (1) + ácido palmítico (2) a $20 \mathrm{mmHg}$.

Tabela 2 - Parâmetros de interação binária. Sistema: palmitato de etila (1) + ácido palmítico (2).

\begin{tabular}{|c|c|c|c|c|}
\hline Modelos de $\mathrm{G}^{\mathrm{E}}$ & $\mathrm{A}_{12}\left(\mathrm{cal}^{\left.\mathrm{m} \mathrm{mol}^{-1}\right)}\right.$ & $\mathrm{A}_{21}\left(\mathrm{cal}^{\mathrm{m}} \mathrm{mol}^{-1}\right)$ & $\alpha_{12}$ & $\begin{array}{c}\text { Desvio Absoluto } \\
\text { Médio em } T\left({ }^{\circ} \mathrm{C}\right)\end{array}$ \\
\hline NRTL & $-775,8458$ & 1412,9447 & 0,2986 & 0,23 \\
\hline UNIQUAC & $-361,3426$ & 477,8494 & - & 0,23 \\
\hline Wilson & 1030,9249 & $-412,2899$ & - & 0,25 \\
\hline
\end{tabular}

Os desvios obtidos para cada um dos sistemas estudados mostram claramente que os modelos NRTL, UNIQUAC e Wilson se ajustaram aos dados experimentais, apresentando desvios muito próximos em cada sistema binário e principalmente dentro da incerteza experimental.

Os resultados obtidos para os dois sistemas estudados são um forte indicativo de que o DSC associado a um sistema de vácuo, juntamente com a metodologia desenvolvida, torna-se uma técnica adequada para a determinação de dados P-T-X.

\section{CONCLUSÃO}

Este estudo foi primordial para que a metodologia que tinha sido aplicada no estudo de pressão de vapor em trabalhos anteriores pudesse ser estendida na investigação do equilíbrio líquido-vapor de misturas binárias. O avanço deste trabalho permitiu determinar dados de grande interesse, principalmente para os processos de produção de biocombustíveis, que dificilmente seriam 
determinados por métodos convencionais. A razão disso está no preço elevado de ácidos graxos e ésteres etílicos graxos, que tornou possível trabalhar com essa técnica associada ao DSC, já que cada ponto de um diagrama de fases é obtido com quantidades entre 4 e $6 \mathrm{mg}$, quantidades essas bem inferiores às utilizadas por outras técnicas, como por exemplo, a ebuliometria.

Os sistemas graxos obtidos no presente estudo apresentaram boa concordância em relação aos modelos Wilson, NRTL e UNIQUAC, que se mostraram adequados na representação da fase líquida, colaborando com novos parâmetros dos modelos termodinâmicos.

\section{REFERÊNCIAS}

AKISAWA SILVA, L. Y.; MATRICARDE FALLEIRO, R.M.; MEIRELLES, A.J.A.; KRÄHENBÜHL, M. A. Determination of the vapor pressure of ethyl esters by differential scanning calorimetry. Journal of Chemical Thermodynamics, vol. 43, p. 943-947, 2011.

CASSERINO, M.; BLEVINS, D. R. e SANDERS, R. N. An improved method for measuring vapor pressure by DSC with automated pressure control. Thermochimica Acta, vol. 284, p. 145-1452, 1996.

DDBST - Dortmund Data Bank Software Package - Educational version - 2003, www.ddbst.de.

KNOTHE, G., KRAHL, J., VAN GERPEN, J. RAMOS, L. P. Manual do Biodiesel. Editora: Edgard Blucher, 2006, $352 \mathrm{p}$.

MATRICARDE FALLEIRO, R. M., AKISAWA SILVA, L. Y., MEIRELlES, A. J. A., KRÄHENBÜHL, M. A. Vapor pressure data for fatty acids obtained using an adaptation of the DSC technique. Thermochimica Acta, vol. 547, p. 6-12, 2012.

SKOOG, D. A.; HOLLER, F. J. e NIEMAN, T. A. Principles of Instrumental Analysis. Saunders Brace College Publishers, 1992. 